\title{
Analgosedation during flexible fiberoptic bronchoscopy: comparing the clinical effectiveness and safety of remifentanil versus midazolam/propofol
}

Hyun Lee ${ }^{1 \dagger}$, Yeong Hun Choe ${ }^{2 \dagger}$ and Seungyong Park P, $^{2 *}$

\begin{abstract}
Background: There are limited data regarding the efficacy and safety of remifentanil sedation for diagnostic bronchoscopy. The aim of this study was to evaluate the clinical efficacy and safety of remifentanil by comparing it with those of conventional drugs, midazolam and propofol.

Methods: A retrospective study of 186 patients who underwent diagnostic bronchoscopy at Chonbuk National University Hospital was performed. Patients were classified into the remifentanil group and midazolam/propofol group according to the drugs used during bronchoscopy.

Results: Of the 186 patients, 111 patients received remifentanil and 75 received midazolam/propofol during the bronchoscopy. The proportion of patients who required bronchoscopy for endobronchial inspection alone was significantly higher in the midazolam/propofol group than in the remifentanil group (93.3\% vs. 73.0\%; $p<0.001$ ). In contrast, the proportion of patients who required more invasive procedures, such as bronchoscopic biopsy, bronchoalveolar lavage, or transbronchial lung biopsy, was significantly higher in the remifentanil group than in the midazolam/propofol group ( $27.0 \%$ vs. $6.7 \% ; p<0.001)$. The recovery time was significantly shorter in the remifentanil group than in the midazolam/propofol group (mean $6.4 \mathrm{~min}$ vs. $11.6 \mathrm{~min}, p<0.001$ ). There were no significant differences between the groups with regard to safety events including desaturation, hypotension, and arrhythmia.
\end{abstract}

Conclusions: Despite the higher proportion of patients who underwent more invasive procedures in the remifentanil group than in the midazolam/propofol group, there was no significant difference in safety events between the groups. Those in the remifentanil group also demonstrated a faster recovery time than those in the midazolam/propofol group.

Keywords: Remifentanil, Midazolam, Propofol, Bronchoscopy, Analgosedation

\footnotetext{
* Correspondence: cough@jbnu.ac.kr

${ }^{\dagger}$ Hyun Lee and Yeong Hun Choe contributed equally to this work.

${ }^{2}$ Department of Internal Medicine, Chonbuk National University

Hospital-Chonbuk National University Medical School, Jeonju, Republic of

Korea

${ }^{3}$ Research Institute of Clinical Medicine of Chonbuk National

University-Biomedical Research Institute of Chonbuk National University

Hospital, Jeonju, Republic of Korea

Full list of author information is available at the end of the article
}

(c) The Author(s). 2019 Open Access This article is distributed under the terms of the Creative Commons Attribution 4.0 International License (http://creativecommons.org/licenses/by/4.0/) which permits unrestricted use, distribution, and reproduction in any medium, provided you give appropriate credit to the original author(s) and the source, provide a link to the Creative Commons license, and indicate if changes were made. The Creative Commons Public Domain Dedication waiver (http://creativecommons.org/publicdomain/zero/1.0/) applies to the data made available in this article, unless otherwise stated. 


\section{Background}

Flexible bronchoscopy remains the gold standard for numerous diagnostic and therapeutic interventions and has become an integral part of pulmonary medicine [1]. Given its widespread use, it is important to select appropriate sedation to relieve the anxiety and pain of patients undergoing bronchoscopy [2-4]. The type of sedation may also be helpful for the bronchoscopist to facilitate the procedure [4].

Although the current guidelines recommend the combined use of an opioid and midazolam for bronchoscopy sedation [3], physicians often use a single drug, or a combination of benzodiazepines, propofol, and opioids in this setting $[5,6]$. In addition, with the development of new drugs, remifentanil and dexmedetomidine have been introduced as options for analgosedation for flexible bronchoscopy in adults [7-10]. Accordingly, the combination of new drugs and conventional drugs has enabled a wide variety of combinations of drugs to be used for analgosedation for flexible bronchoscopy. Several studies have demonstrated the safety and efficacy of the addition of remifentanil or dexmedetomidine (to conventional drugs) in adult patients who underwent flexible bronchoscopy [7-10]. However, the best-standardized practice for the use of sedation during bronchoscopy has yet to be determined.

Remifentanil is an ultra short-acting new opioid analgesic drug that is commonly used to relieve pain during the surgery and as adjunctive to an anesthetic [11]. The ultrafast offset and short half-life also make it an ideal drug for analgosedation in intensive care unit (ICU) patients [12]. Considering that remifentanil has excellent analgosedation effects with an advantage of the short half-life, remifentanil could become an alternative to conventional treatments (including the combination of a benzodiazepine and propofol) for sedation in bronchoscopy. However, few studies have compared the effectiveness and safety profile of remifentanil versus a combination of midazolam and propofol. Therefore, the aim of this study was to compare the effectiveness and safety of analgosedation using remifentanil versus the combination of midazolam and propofol during flexible bronchoscopy.

\section{Methods}

\section{Study design and population}

This retrospective observational study was conducted at a tertiary university-affiliated hospital from May 2015 to September 2017. It was approved by the local Institutional Review Board (IRB no. CUH 2019-06-028). The patients were stratified into the remifentanil group and midazolam/propofol group according to the drugs used during flexible bronchoscopy.

\section{Flexible bronchoscopy}

Flexible fiberoptic bronchoscopy was performed with standard fiberscopes by two professional pulmonologists.
A flexible bronchoscope (BF-F260, BF-6C260, 1 T260, BF-Q290, 1TQ290, Olympus, Tokyo, Japan) was inserted via the nasal approach with subjects in the supine position.

All consecutive patients who were spontaneously breathing were eligible. All patients had fasted for at least 8 hours prior to the start of the procedure and had an intravenous catheter. Topical anesthesia was performed using $4 \%$ lidocaine spray in the oral cavity. While the vocal cords and carina were visualized, $4 \mathrm{ml}$ of $2 \%$ lidocaine was delivered through the bronchoscope channel to suppress cough. Additional topical anesthesia was applied to the major bronchi as needed (at the bronchoscopists' discretion) for a maximum total lidocaine dose of $7 \mathrm{mg} / \mathrm{kg}$.

\section{Sedation}

\section{Midazolam/propofol group}

Pretreatment with 1-2 mg midazolam (Midazolam ${ }^{\oplus}$, Bukwang, Seoul, Republic of Korea) was used to relieve significant preprocedural anxiety. Patients were treated with an additional $1 \mathrm{mg}$ of midazolam if necessary. Next, propofol (Anepol ${ }^{\oplus}$, Hana Pharmaceutical Co., Seoul, Republic of Korea) was administered according to our hospital's protocol.

\section{Remifentanil group}

Patients received no premedication in the remifentanil group. Remifentanil (Ultiva ${ }^{\circledR}$, GlaxoSmithKline, Seoul,

Table 1 Baseline characteristics

\begin{tabular}{|c|c|c|c|}
\hline & $\begin{array}{l}\text { Remifentanil } \\
\text { group } \\
(n=111)\end{array}$ & $\begin{array}{l}\text { Midazolam / propofol } \\
\text { group }(n=75)\end{array}$ & $p$ \\
\hline Age, years & $59.0(51.0-70.5)$ & $58.0(42.0-71.5)$ & 0.158 \\
\hline Sex, male & $51(45.9)$ & $29(38.7)$ & 0.405 \\
\hline $\begin{array}{l}\text { Body mass index } \\
\mathrm{kg} / \mathrm{m}^{2}\end{array}$ & $22.0(20.0-24.0)$ & $22.0(20.0-24.5)$ & 0.630 \\
\hline \multicolumn{4}{|l|}{ Comorbidities } \\
\hline Hypertension & $33(29.7)$ & $17(22.7)$ & 0.370 \\
\hline Diabetes mellitus & $12(10.8)$ & $4(5.3)$ & 0.298 \\
\hline Asthma & $1(0.9)$ & $2(2.7)$ & 0.730 \\
\hline $\begin{array}{l}\text { Chronic obstructive } \\
\text { pulmonary disease }\end{array}$ & $2(1.8)$ & $2(2.7)$ & 1.000 \\
\hline $\begin{array}{l}\text { Chronic heart } \\
\text { disease }\end{array}$ & $6(5.4)$ & $4(5.3)$ & 1.000 \\
\hline \multicolumn{4}{|l|}{ Pulmonary function } \\
\hline FVC, L & $2.9(2.4-3.5)$ & $3.1(2.6-3.7)$ & 0.129 \\
\hline FVC, \% predicted & $94.0(85.0-102.0)$ & $99.0(88.5-107.5)$ & 0.076 \\
\hline $\mathrm{FEV}_{1}, \mathrm{~L}$ & $2.3(1.8-2.7)$ & $2.4(1.9-2.8)$ & 0.538 \\
\hline $\mathrm{FEV}_{1}, \%$ predicted & $99.0(90.0-111.0)$ & $102.5(91.0-111.0)$ & 0.691 \\
\hline $\mathrm{FEV}_{1} / \mathrm{FVC}$ & $78.0(73.0-82.5)$ & $76.0(71.0-82.5)$ & 0.726 \\
\hline
\end{tabular}

Data are present as number (\%) or median (interquartile range) FVC Forced expiratory volume, FEV Forced expiratory volume in $1 \mathrm{~s}$ 
Republic of Korea) was initially administered with a bolus dose of the study drug $(0.5-1 \mathrm{mcg} / \mathrm{kg})$, followed by a $0.02-0.04 \mathrm{mcg} / \mathrm{kg} / \mathrm{min}$ continuous infusion at the discretion of the bronchoscopist. A bolus dose of the study drug in proportional volumes was administered slowly (over a period of $60 \mathrm{~s}$ ) to minimize known adverse effects, such as respiratory depression, hypotension, and bradycardia. The fiberscope was inserted into the patient 3-5 min after the remifentanil initial onset time. The remifentanil infusion was immediately stopped if bradypnea/apnea or hemodynamic collapse occurred.

\section{Outcome variables}

The primary outcomes included the incidences of oxygen desaturation and oxygen saturation trend between the two groups. Oxygen desaturation was defined as an oxygen saturation $<90 \%$ for more than 10 s. In the event of oxygen desaturation, oxygen delivery was increased from 4 to $10 \mathrm{~L} / \mathrm{min}$. Additional assistance (including reservoir bag-mask, high flow nasal cannula, and intubation followed by bag valve mask ventilation) was performed in a stepwise manner as needed. Secondary outcomes included hemodynamic variables, the incidence of hemodynamic adverse events, and recovery time.

Vital signs were continuously monitored before, during, and after the procedure by the bronchoscopist and nurses. Bradycardia (defined by a heart rate $<60$ beats/ min or a decrease of $>15$ beats/min from baseline) was treated with intravenous atropine $0.5 \mathrm{mg}$. Hypotension (defined by a systolic blood pressure $<90 \mathrm{mmHg}$ or a decrease of $>20 \mathrm{mmHg}$ from baseline) was treated with intravenous epinephrine $5 \mathrm{mg}$. Bradypnea (defined by a respiratory rate $<12 / \mathrm{min}$ or apnea $>10 \mathrm{~s}$ ), and other adverse reactions were noted throughout the procedure.

After the bronchoscopy, the patient was moved to the recovery room. In the recovery room, the recovery of the patient was assessed using the modified Aldrete score [13] every 3-5 min by the attending nurses. Recovery time was defined as the time taken after the end of bronchoscopy until the recovery, which was defined $\geq 9$ for the modified Aldrete score [13]. Recovery time was classified as fast and delayed according to the median value of recovery time.

\section{Statistical analysis}

Continuous variables are presented as mean (standard deviation $[\mathrm{SD}]$ ) or median (interquartile range, [IQR]). Categorical variables are presented as counts (\%). Continuous variables were compared using the MannWhitney $\mathrm{U}$ test or T-test for continuous variables. Categorical variables were compared using the chi-square test or Fischer's exact test, as appropriate. In order to evaluate the factors associated with fast recovery time, we performed univariable and multivariable logistic regression analyses. The following factors were included in the multivariable model: age, sex, body mass index, chronic obstructive pulmonary disease or asthma, chronic heart disease, bronchoscopy indication, procedure, and type of sedative drugs. Two-sided $p$ values < 0.05 were considered significant. All statistical analyses were performed using $\mathrm{R}$ (ver. 3.2.3; $\mathrm{R}$ Foundation for Statistical Computing, Vienna, Austria) and STATA version 15 (StataCorp LP, College Station, TX, USA).

\section{Results}

Patients

The baseline characteristics are summarized in Table 1 . There were no significant differences between the two groups with regard to age, sex, body mass index, comorbidities such as hypertension, diabetes mellitus, asthma, chronic obstructive pulmonary disease, and chronic heart disease, or pulmonary function.

\section{Indication for bronchoscopy and use of sedative drugs}

Infection, lung cancer, and hemoptysis were common indications of bronchoscopy in the remifentanil group in order of frequency. In comparison, infection, hemoptysis, and lung cancer were common indications of bronchoscopy in the midazolam/propofol group (Table 2). Patients in the remifentanil group were more likely to undergo invasive procedures during the bronchoscopy (beyond inspection alone) than were those in the midazolam/propofol group. The median procedure time was $9 \mathrm{~min}$ (IQR, 8-10 min) in the remifentanil group vs. $11 \mathrm{~min}$ (IQR, 10-13 min) in the midazolam/ propofol group $(p<0.001)$. The remifentanil group received a median of $0.2 \mu \mathrm{g} / \mathrm{kg} / \mathrm{min}$ (IQR, $0.18-0.33 \mu \mathrm{g} /$ $\mathrm{kg} / \mathrm{min}$ ) of remifentanil. The midazolam/propofol group received a median of $2 \mathrm{mg}$ of midazolam (IQR, $0-4 \mathrm{mg}$ ) and $50.2 \mu \mathrm{g} / \mathrm{kg} / \mathrm{min}(39.0-64.3 \mu \mathrm{g} / \mathrm{kg} / \mathrm{min})$ of propofol.

\section{Comparing the adverse events and recovery time between groups}

There were no significant differences in oxygen desaturation, lowest peripheral capillary oxygen saturation, heart rate, antidote use, or sedation discontinuation between the remifentanil group and midazolam/propofol group. However, hypertension, defined by a blood pressure $>150 / 90 \mathrm{mmHg}$ was significantly more common in the remifentanil group than it was in the propofol/midazolam group (52.3\% vs. $30.7 \% ; p=0.008)$. In contrast, the recovery time was significantly lower in the remifentanil group than in the midazolam/propofol group (mean $\pm \mathrm{SD}, 6.4 \pm 3.0 \mathrm{~min}$ vs. $11.6 \pm 4.0 \mathrm{~min}, p<0.001$ ) (Table 3). 
Table 2 Indication for bronchoscopy and the use of sedative drugs

\begin{tabular}{|c|c|c|c|}
\hline & $\begin{array}{l}\text { Remifentanil } \\
\text { group } \\
(n=111)\end{array}$ & $\begin{array}{l}\text { Midazolam / } \\
\text { propofol group }(n=75)\end{array}$ & p \\
\hline \multicolumn{3}{|c|}{ Indication for bronchoscopy } & 0.137 \\
\hline Infection & $45(40.5)$ & $40(53.3)$ & \\
\hline Lung cancer & $19(17.1)$ & $6(8.0)$ & \\
\hline Hemoptysis & $13(11.7)$ & $12(16.0)$ & \\
\hline $\begin{array}{l}\text { Interstitial lung } \\
\text { disease }\end{array}$ & $2(1.8)$ & $0(0)$ & \\
\hline Others & $32(28.8)$ & $17(22.7)$ & \\
\hline Procedure & & & 0.005 \\
\hline $\begin{array}{l}\text { Endobronchial } \\
\text { inspection only }\end{array}$ & $81(73.0)$ & $70(93.3)$ & \\
\hline $\begin{array}{l}\text { Endobronchial } \\
\text { inspection with } \\
\text { bronchoscopic } \\
\text { biopsy }\end{array}$ & $20(18.0)$ & $1(1.3)$ & \\
\hline $\begin{array}{l}\text { Endobronchial } \\
\text { inspection with } \\
\text { BAL and TBLB }\end{array}$ & $2(1.8)$ & $0(0.0)$ & \\
\hline $\begin{array}{l}\text { Endobronchial } \\
\text { inspection with BAL }\end{array}$ & $8(7.2)$ & $4(5.3)$ & \\
\hline $\begin{array}{l}\text { Procedure duration, } \\
\text { min }\end{array}$ & $9(8-10)$ & $11(10-13)$ & $<0.001$ \\
\hline \multicolumn{4}{|l|}{ Sedative drugs } \\
\hline Midazolam dose, mg & - & $2(0-4)$ & \\
\hline $\begin{array}{l}\text { Propofol dose rate, } \\
\mathrm{ug} / \mathrm{kg} / \mathrm{min}\end{array}$ & - & $50.2(39.0-64.3)$ & \\
\hline $\begin{array}{l}\text { Remifentanil dose } \\
\text { rate, } u g / \mathrm{kg} / \mathrm{min}\end{array}$ & $\begin{array}{l}0.2 \\
(0.2-0.3)\end{array}$ & & \\
\hline
\end{tabular}

Data are present as number (\%) or median (interquartile range)

$B A L$ Bronchoalveolar lavage, TBLB Transbronchial lung biopsy

\section{The relationship between remifentanil use and recovery} time

In both univariable and multivariable analyses, the use of remifentanil was associated with more rapid recovery than was the use of midazolam/propofol (unadjusted odds ratio $=7.70,95 \%$ confidence interval $=2.74-21.65$; adjusted odds ratio $=15.88$, 95\% confidence interval $=$ 4.14-60.90) (Table 4).

\section{Discussion}

We evaluated 186 subjects who underwent flexible bronchoscopy under sedation. Approximately 60\% of these patients received remifentanil, while the remaining $40 \%$ received a combination of midazolam and propofol for procedural sedation. The patients in the remifentanil group were more likely to undergo invasive procedures during bronchoscopy (such as bronchoscopic biopsy, bronchoalveolar lavage, or transbronchial lung biopsy) than those in the midazolam/propofol group. Despite this finding, there was no significant difference between
Table 3 Comparing adverse events and recovery time across groups

\begin{tabular}{llll}
\hline & $\begin{array}{l}\text { Remifentanil } \\
\text { group } \\
(n=111)\end{array}$ & $\begin{array}{l}\text { Midazolam / propofol } \\
\text { group }(n=75)\end{array}$ & $p$ \\
\hline $\begin{array}{l}\text { Desaturation } \\
\text { Lowest } \mathrm{SpO}_{2}\end{array}$ & $9(8.1)$ & $6(8.0)$ & 1.000 \\
Heart rate & $73.2 \pm 12.3$ & $81.8 \pm 6.0$ & 0.174 \\
$\quad \begin{array}{l}\text { Tachycardia } \\
\text { Bradycardia }\end{array}$ & $5(4.5)$ & $1(1.3)$ & 0.294 \\
$\begin{array}{l}\text { Blood pressure } \\
\quad \text { Highest }\end{array}$ & $58(52.3)$ & $23(30.7)$ & \\
$\begin{array}{l}\text { BP }>150 / 90 \mathrm{mmHg} \\
\text { Lowest }\end{array}$ & $0(0)$ & $1(1.3)$ & \\
$\begin{array}{l}\text { BP }<90 / 60 \mathrm{mmHg} \\
\text { Recovery time, min }\end{array}$ & $6.4 \pm 3.0$ & $11.6 \pm 4.0$ & \\
Antidote use & $2(1.8)$ & $1(1.3)$ & 1.008 \\
$\begin{array}{l}\text { Sedation medication } \\
\text { discontinuation }\end{array}$ & $7(6.3)$ & $5(6.7)$ & 1.0 \\
\hline
\end{tabular}

Data are present as number (\%) or mean (standard deviation)

Tachycardia and bradycardia were defined as HR $>100 /$ min and $\mathrm{HR}<60 / \mathrm{min}$, respectively

$\mathrm{SpO}_{2}$ Peripheral capillary oxygen saturation, $\mathrm{HR}$ Heart rate

the groups in the occurrence of adverse safety events, including oxygen desaturation, hypotension, and arrhythmia. In addition, the recovery time was significantly shorter in the remifentanil group than in the midazolam/propofol group.

Ideal drugs for procedural sedation and analgesia (PSA), or "conscious sedation," have a rapid onset and short duration of action, and maintain hemodynamic stability with no major side effects [14]. The classically used sedative drugs include the single or combined use of benzodiazepines, propofol, and opioids. A 2003 United Kingdom survey found that $78 \%$ of bronchoscopists routinely use midazolam sedation alone and that midazolam plus fentanyl/alfentanil was the most frequently combined regimen [15]. Another study found that the most commonly used drugs in Switzerland were midazolam (46\%) and propofol (77\%) [5]. However, unfortunately, there are no clear recommendations favoring one sedation regimen over another. The introduction of new sedative drugs, such as remifentanil and dexmedetomidine, has added to the complexity of combining sedative regimens [7-10].

Analgosedation refers to the use of an analgesic drug (usually an opioid) before a sedative is used to reach the sedative goal [16]. Analgosedation is preferred over the sedative-hypnotic approach in critically ill patients, for whom the primary goal is to address pain and discomfort before adding hypnotic agents [16]. The use of analgosedation has increased substantially over time and is accepted as a common protocol in the management of 
Table 4 Factors associated with rapid recovery in patients undergoing sedative bronchoscopy

\begin{tabular}{|c|c|c|c|c|}
\hline & \multicolumn{2}{|l|}{ Univariable analysis } & \multicolumn{2}{|l|}{ Multivariable analysis } \\
\hline & Unadjusted OR (95\% Cl) & $p$ & Adjusted OR (95\% Cl) & $p$ \\
\hline Age, yr & $0.98(0.95-1.01)$ & 0.131 & $0.97(0.93-1.001)$ & 0.059 \\
\hline Female & $0.71(0.30-1.71)$ & 0.448 & $0.53(0.18-1.54)$ & 0.241 \\
\hline Body mass index, $\mathrm{kg} / \mathrm{m}^{2}$ & $0.93(0.93-1.11)$ & 0.772 & $0.92(0.82-1.04)$ & 0.195 \\
\hline COPD or asthma & $0.37(0.07-2.01)$ & 0.249 & $0.93(0.11-7.76)$ & 0.946 \\
\hline Chronic heart disease & $2.74(0.76-9.91)$ & 0.123 & $0.62(0.09-4.32)$ & 0.628 \\
\hline \multicolumn{5}{|l|}{ Indication } \\
\hline Others & Ref & & Ref & \\
\hline Lung cancer & $0.53(0.15-1.95)$ & 0.343 & $0.69(0.13-3.66)$ & 0.665 \\
\hline Infection & $0.90(0.31-2.59)$ & 0.841 & $1.43(0.40-5.05)$ & 0.581 \\
\hline Interstitial lung disease & $0.98(0.22-4.28)$ & 0.976 & $1.72(0.29-10.06)$ & 0.548 \\
\hline \multicolumn{5}{|l|}{ Procedure } \\
\hline Inspection only & Ref & & Ref & \\
\hline Inspection with bronchoscopic biopsy & $0.92(0.25-3.39)$ & 0.896 & $0.27(0.04-1.64)$ & 0.154 \\
\hline Inspection with BAL and/or TBLB & $0.92(0.19-4.40)$ & 0.913 & $0.67(0.10-4.55)$ & 0.684 \\
\hline \multicolumn{5}{|l|}{ Sedative drug } \\
\hline Midazolam/propofol & Ref & & Ref & \\
\hline Remifentanyl & $7.70(2.74-21.65)$ & $<0.001$ & $15.88(4.14-60.90)$ & $<0.001$ \\
\hline
\end{tabular}

ICU patients in many hospitals [16]. Accumulating data have suggested that analgosedation is safe and effective for the management of very vulnerable ICU patients. Although these data also suggest that analgosedation is safe for use during fiberoptic bronchoscopy, there is little evidence supporting this practice.

Remifentanil is a potent, selective $\mu$-opioid receptor agonist that is metabolized by blood and tissue esterases independent of organ function [17]. Remifentanil has a rapid onset and a short duration of action (half-life $<10$ min) with no tissue accumulation. The advantage of this drug is that its effect does not last long after it is stopped. Thus, one of the most important advantages of this drug is that it can be safely used in patients with organ impairment such as acute kidney injury and severe liver disease [18-20]. It also provides good hemodynamic stability [21]. Another advantage of remifentanil is that it effectively suppresses cough [22], which seems suitable for PSA during fiberoptic bronchoscopy.

Interestingly, despite several advantages of remifentanil, its utility for PSA in patients undergoing fiberoptic bronchoscopy has not been well elucidated. Two studies showed that the use of remifentanil alone is safe in ICU patients $[9,10]$. Another study showed that remifentanil attenuates the hemodynamic response to rigid bronchoscopy without an increase of hypotension or bradycardia [23]. However, most other studies regarding remifentanil studied its use in combination with other drugs [7, 24, 25]. For example, Ryu and colleagues showed that the use of remifentanil plus propofol was associated with a shorter recovery time than was that of dexmedetomidine. However, the combination of remifentanil and propofol during bronchoscopy led to a higher incidence of desaturation and a need for oral cavity suctioning than did dexmedetomidine use [7]. Therefore, it is unclear whether remifentanil can be safely and effectively used alone for PSA during fiberoptic bronchoscopy. From this perspective, our study provides important evidence that remifentanil can be used alone for PSA during fiberoptic bronchoscopy including cases that require complex procedures. In addition, we found that remifentanil use was associated with faster recovery time and comparable adverse events to those of midazolam/propofol use. The reasons for shorter procedure duration with remifentanil relative to midazolam/propofol are not fully explainable. Given the shorter half-life and stability of remifentanil compared to those of midazolam/propofol, the attending physicians might have given enough remifentanil to allow patients to be sufficiently sedated during bronchoscopy. On the other hand, patients receiving midazolam/propofol with relatively long half-lives may have been less sedated than those receiving remifentanil. However, since we did not compare the depth of sedation between the two groups, further studies are needed to confirm this suggestion. 
One strength of our study is that it raises important questions regarding the clinical usefulness of remifentanil use alone for analgosedation during fiberoptic bronchoscopy. To the best of our knowledge, this is the first study to comprehensively evaluate the clinical utility and safety of remifentanil use in fiberoptic bronchoscopy in comparison with those of midazolam/propofol. Another strength of our study is that we employed a larger study population than did prior studies that evaluated the use of remifentanil alone during fiberoptic bronchoscopy. Regardless, this study also has several limitations. First, it has an inherent bias due to its retrospective design. It was also performed in a single university hospital. The second limitation is that the analgosedation drugs used in each patient were chosen at the discretion of the attending physicians. Therefore, this discretion may have resulted in the more frequent use of remifentanil (over conventional drugs) in vulnerable patients or in those who required more complex procedures. Therefore, the remifentanil group was more prone to include patients with disadvantageous clinical characteristics than was the midazolam/propofol group. Despite this limitation, we found that there were no significant differences between the groups with regard to adverse events. Third, we were unable to assess patient satisfaction scores and the level of sedation, which are important measures. Fourth, we could not assess the total dose of topical lidocaine used during the procedures.

\section{Conclusions}

Despite a higher proportion of patients who underwent more invasive procedures in the remifentanil group than in the midazolam/propofol group, there was no significant difference in the occurrence of safety events between the groups. Furthermore, the recovery time was faster in the remifentanil group than it was in the midazolam/propofol group. Our findings suggest that remifentanil alone may be safely and effectively used for PSA during fiberoptic bronchoscopy. Further prospective comparative evaluation is required to establish its superiority and cost-effectiveness over other contemporary drugs.

\section{Abbreviations}

Cl: Confidence interval; ICU: Intensive care unit; IQR: Interquartile range; PSA: Procedural sedation and analgesia; SD: Standard deviation

\section{Acknowledgments}

Not applicable.

\section{Authors' contributions}

Conception and design: HL, YHC, SP; Data analysis: HL, SP; Data interpretation and manuscript writing: $\mathrm{HL}, \mathrm{YHC}, \mathrm{SP}$; Revision of the manuscript and contribution to intellectual content: $\mathrm{HL}, \mathrm{YHC}, \mathrm{SP} ; \mathrm{SP}$ is the guarantor of the manuscript. All authors have read and approved the manuscript.

\section{Funding}

This paper was supported by the Fund of Biomedical Research Institute, Chonbuk National University Hospital. Chonbuk National University Hospital played no role in the design of this study and collection, analysis, and interpretation of data, and writing of the manuscript.

Availability of data and materials

All data extracted in this study are included in this article.

\section{Ethics approval and consent to participate}

The study protocol has been approved by the Institutional Review Board of Chonbuk National University Hospital (CUH 2019-05-083). Given the retrospective nature of the study and the use of anonymized patient data, the requirement for informed consent was waived.

\section{Consent for publication}

Not applicable.

\section{Competing interests}

The authors declare that they have no competing interests.

\section{Author details}

${ }^{1}$ Division of Pulmonary Medicine and Allergy, Department of Internal Medicine, Hanyang University Hospital, Seoul, Republic of Korea. ${ }^{2}$ Department of Internal Medicine, Chonbuk National University Hospital-Chonbuk National University Medical School, Jeonju, Republic of Korea. ${ }^{3}$ Research Institute of Clinical Medicine of Chonbuk National University-Biomedical Research Institute of Chonbuk National University Hospital, Jeonju, Republic of Korea.

Received: 8 June 2019 Accepted: 21 November 2019

Published online: 09 December 2019

\section{References}

1. Panchabhai TS, Mehta AC. Historical perspectives of bronchoscopy. Connecting the dots. Ann Am Thorac Soc. 2015;12(5):631-41.

2. Poi PJ, Chuah SY, Srinivas P, Liam CK. Common fears of patients undergoing bronchoscopy. Eur Respir J. 1998;11(5):1147-9.

3. Du Rand IA, Blaikley J, Booton R, Chaudhuri N, Gupta V, Khalid S, Mandal S, Martin J, Mills J, Navani N, et al. British Thoracic Society guideline for diagnostic flexible bronchoscopy in adults: accredited by NICE. Thorax. 2013;68(Suppl 1):i1.

4. José RJ, Shaefi S, Navani N. Sedation for flexible bronchoscopy: current and emerging evidence. Eur Respir Rev. 2013;22(128):106.

5. Gaisl T, Bratton DJ, Heuss LT, Kohler M, Schlatzer C, Zalunardo MP, Frey M, Franzen D. Sedation during bronchoscopy: data from a nationwide sedation and monitoring survey. BMC Pulm Med. 2016;16(1):113.

6. Müller T, Thümmel K, Cornelissen CG, Krüger S, Dreher M. Analogosedation during flexible bronchoscopy using a combination of midazolam, propofol and fentanyl - a retrospective analysis. PLoS One. 2017;12(4):e0175394.

7. Ryu JH, Lee SW, Lee JH, Lee EH, Do SH, Kim CS. Randomized double-blind study of remifentanil and dexmedetomidine for flexible bronchoscopy. Br J Anaesth. 2012;108(3):503-11.

8. Gao Y, Kang K, Liu H, Jia L, Tang R, Zhang X, Wang H, Yu K. Effect of dexmedetomidine and midazolam for flexible fiberoptic bronchoscopy in intensive care unit patients: a retrospective study. Medicine. 2017;96(25): e7090.

9. Chalumeau-Lemoine L, Stoclin A, Billard V, Laplanche A, Raynard B, Blot F. Flexible fiberoptic bronchoscopy and remifentanil target-controlled infusion in ICU: a preliminary study. Intensive Care Med. 2013;39(1):53-8.

10. Rezaiguia-Delclaux S, Laverdure F, Kortchinsky T, Lemasle L, Imbert A, Stephan F. Fiber optic bronchoscopy and remifentanil target-controlled infusion in critically ill patients with acute hypoxaemic respiratory failure: a descriptive study. Anaesth Crit Care Pain Med. 2017;36(5):273-7.

11. Westmoreland CL, Hoke JF, Sebel PS, Hug CC Jr, Muir KT. Pharmacokinetics of remifentanil (Gl87084B) and its major metabolite (GI90291) in patients undergoing elective inpatient surgery. Anesthesiology. 1993;79(5):893-903.

12. Karabinis A, Mandragos K, Stergiopoulos S, Komnos A, Soukup J, Speelberg B, Kirkham AJT. Safety and efficacy of analgesia-based sedation with remifentanil versus standard hypnotic-based regimens in intensive care unit 
patients with brain injuries: a randomised, controlled trial [ISRCTN50308308]. Crit Care. 2004;8(4):R268-80.

13. Aldrete JA. The post-anesthesia recovery score revisited. J Clin Anesth. 1995; 7(1):89-91.

14. Morris LG, Zeitler DM, Amin MR. Unsedated flexible fiberoptic bronchoscopy in the resident clinic: technique and patient satisfaction. Laryngoscope. 2007;117(7):1159-62.

15. Pickles J, Jeffrey M, Datta A, Jeffrey AA. Is preparation for bronchoscopy optimal? Eur Respir J. 2003;22(2):203-6.

16. Devlin JW, Skrobik Y, Gélinas C, Needham DM, Slooter AJC, Pandharipande PP, Watson PL, Weinhouse GL, Nunnally ME, Rochwerg B, et al. Clinical practice guidelines for the prevention and management of pain, agitation/ sedation, delirium, immobility, and sleep disruption in adult patients in the ICU. Crit Care Med. 2018;46(9):e825-73.

17. Burkle H, Dunbar S, Van Aken H. Remifentanil: a novel, short-acting, muopioid. Anesth Analg. 1996;83(3):646-51.

18. Breen D, Wilmer A, Bodenham A, Bach V, Bonde J, Kessler P, Albrecht S, Shaikh $\mathrm{S}$. The offset of pharmacodynamic effects of remifentanil in ICU patients is not affected by renal impairment. In: Intensive care medicine: 2001. New York: Springer-Verlag; 2001. p. S207.

19. Hoke JF, Shlugman D, Dershwitz M, Michałowski P, Malthouse-Dufore S, Connors PM, Martel D, Rosow CE, Muir KT, Rubin N. Pharmacokinetics and pharmacodynamics of remifentanil in persons with renal failure compared with healthy volunteers. Anesthesiology. 1997;87(3):533-41.

20. Dershwitz M, Hoke JF, Rosow CE, Michalowski P, Connors PM, Muir KT, Dienstag JL. Pharmacokinetics and pharmacodynamics of remifentanil in volunteer subjects with severe liver disease. Anesthesiology. 1996;84(4):812-20.

21. Gemma M, Tommasino C, Cozzi S, Narcisi S, Mortini P, Losa M, Soldarini A. Remifentanil provides hemodynamic stability and faster awakening time in Transsphenoidal surgery. Anesth Analg. 2002;94(1):163-8.

22. Lim JH, Ryu SJ, Lim YS. The incidence of cough induced by remifentanil during anesthetic induction was decreased by graded escalation of the remifentanil concentration. Korean J Anesthesiol. 2010;58(2):117-21.

23. Prakash N, McLeod T, Gao Smith F. The effects of remifentanil on haemodynamic stability during rigid bronchoscopy. Anaesthesia. 2001;56(6):576-80.

24. Reyle-Hahn M, Niggemann B, Max M, Streich R, Rossaint R. Remifentanil and propofol for sedation in children and young adolescents undergoing diagnostic flexible bronchoscopy. Paediatr Anaesth. 2000;10(1):59-63.

25. Berkenbosch JW, Graff GR, Stark JM, Ner Z, Tobias JD. Use of a remifentanilpropofol mixture for pediatric flexible fiberoptic bronchoscopy sedation. Paediatr Anaesth. 2004;14(11):941-6.

\section{Publisher's Note}

Springer Nature remains neutral with regard to jurisdictional claims in published maps and institutional affiliations.

Ready to submit your research? Choose BMC and benefit from:

- fast, convenient online submission

- thorough peer review by experienced researchers in your field

- rapid publication on acceptance

- support for research data, including large and complex data types

- gold Open Access which fosters wider collaboration and increased citations

- maximum visibility for your research: over $100 \mathrm{M}$ website views per year

At $\mathrm{BMC}$, research is always in progress.

Learn more biomedcentral.com/submissions 